\title{
THE PHYLETIC STATUS OF THE GENUS PLANARIA (PLATYHELMINTHES, TURBELLARIA, TRICLADIDA)
}

\author{
by
}

\begin{abstract}
IAN R. BALL
Department of Biology, University of Waterloo, Ontario, Canada, and Institute of Taxonomic Zoology, University of Amsterdam, The Netherlands
\end{abstract}

$\&$

\section{NICOLE GOURBAULT}

\section{Laboratoire de Zoologie (Vers), Muséum National d'Histoire Naturelle, Paris, France}

\begin{abstract}
The amphiatlantic distribution of the genus Planaria is incompatible with our current hypothesis of the historical biogeography of freshwater planarians. New anatomical studies suggest the possibility that the genus is not strictly monophyletic; new karyological data are strongly corroborative of that conclusion. The karyotypes of the American species of Planaria are almost identical with those of many other North American Planariidae and quite distinct from that of the European species. These findings are inconsistent with the hypothesis that the species of Planaria form a strictly monophyletic group. Therefore the amphiatlantic disjunction is apparent, not real, and the earlier biogeographical hypothesis is protected from one potential falsifier.
\end{abstract}

\section{INTRODUCTION}

This paper is a sequel to an earlier essay by Ball (1975) on the formulation of biogeographical hypotheses. In that essay a hypothesis was erected to account in historical terms for the known distribution of freshwater planarians throughout the world. One of the critical factors of that hypathesis concerned certain holarctic genera, and in particular the genus Planaria. As at present conceived (Kenk, 1969; Ball et al., 1969) this genus comprises two species in eastern North America and one wide-spread in Europe [a single record of a species endemic to northern India (Whitehouse, 1913) has never been substantiated and it is doubtful that the record is valid].

This amphiatlantic distribution pattern (Ball, 1975: fig. 11) was deemed to be incompatible with the historical hypothesis put forward for reasons that are discussed fully in the earlier paper. In short, that hypothesis failed if the genus Planaria formed a strictly monophyletic group. Since the explanatory value of the hypothesis was high the prediction was made that future work would demonstrate that the European species and the American species most probably did not share an ancestor in common more recently than each did with other Planariidae of Europe and North America, respectively. Thus, the falsification of the hypothesis that the genus Planaria is a monophyletic group protects the larger biogeographical hypothesis from its own potential falsifier.

In the present paper we present karyological and comparative anatomical data from which we conclude, as predicted, that the distribution of the genus Planaria does not falsify the earlier hypothesis because the amphiatlantic disjunction is apparent, not real (Ball, 1975: 418).

\section{MATERIALS AND METHODS}

The species used for this study, and their provenances, were as follows:

Planaria dactyligera dactyligera Kenk, 1935. Twin Springs near Mountain Lake, Giles County, Virginia, U.S.A. Collected by Ian R. Ball and Nicole Gourbault, 2 October 1975.

Planaria dactyligera musculosa Kenk, 1969. Ossippee, Alamance County, North Carolina, U.S.A. Collected by Ian R. Ball and Nicole Gourbault, 14 September 1975.

Planaria torva (Müller, 1774). Rivière Slack, Beuvrequen near Marquise, Pas-de-Calais, France. Collected by Liesbeth de Vries and Hilde Veenstra, 10 February 1977.

All these forms were studied both morphologically and karyologically. Sections were stained with Mallory-Heidenhain; in all other respects the methods of study were those of our previous work (Ball \& Gourbault, 1975).

\section{MORPHOLOGICAL CONSIDERATIONS}

Currently the family Planariidae contains almost 80 species comprising seven genera (Ball, 1977). Over half the species are included in the genus Phagocata which is defined only by primitive 
characters and cannot be regarded as strictly monophyletic (Ball, 1975: note 19). Most of the remaining genera are defined monothetically. The species of Planaria differ from those of Phagocata in only one respect, viz., in their possession of an adenodactyl of a certain type in the copulatory apparatus. The monophyly of the genus therefore depends upon the correct assessment of homologous relationships between the adenodactyls of the various species.

Adenodactyls, or musculo-gland organs, are common accessory organs in the copulatory apparatus of many Turbellaria. Within the aquatic planarians they are rare in the marine forms but they are of wide occurrence in the Paludicola, the inhabitants of fresh waters. It has long been known, however, that there are several different types of adenodactyl and that these have been acquired independently in different genera and species groups.

In his long-standing revision of the freshwater planarians, Kenk (1930) distinguished between three highly differentiated types of adenodactyls, and several minor, or lesser known ones. Of the three major types the solid adenodactyls of the Polycelis tenuis-type, and the characteristically muscularized hollow adenodactyls of the Dendrocoelum lacteum-type need not concern us further here. Of more immediate relevance is the adenodactyl of the Planaria torva-type (fig. 1A). This type is usually strongly curved, with a distinct lumen, is always present singly, and has a large fingerlike papilla that projects into an outgrowth of the genital atrium. The musculature is powerful, consisting primarily of circularly orientated fibres; the dactylose papilla also has circular and longitudinal fibres that are continuous with those of the atrial wall. The lumen of the organ is narrow, lined with a low nucleate epithelium, and is often filled with an eosinophil secretion which also can be seen within the musculature and the surrounding mesenchyme. Presumably the related glands pierce the adenodactyl. The nuclei of the adenodactyl muscles form a layer around the organ. The total appearance is that of a discrete, strongly muscular organ embedded in the mesenchyme laterally to the penis and projecting into the genital atrium.
In his original description of Planaria dactyligera, Kenk (1935) described its adenodactyl as being of the Planaria torva-type. Superficially they may appear to be similar, but in detail they are not. The adenodactyl of $P$.d. dactyligera (fig. 1B) is never curved and whereas the musculature is principally circular there are numerous longitudinal fibres scattered throughout the organ and at its boundaries. The organ is entirely posterior to the male atrium, not lateral to it, and thus it is directed posterio-dorsally and not antero-dorsally. There is no distinct papilla and the unusually spacious lumen possesses a cuboidal nucleate epithelium that is clearly continuous with that of the atrial wall. As in $P$. torva the musculature is surrounded by a zone of nuclei and is pierced with numerous gland cells whose secretion fills the lumen. However, the musculature is very uneven, there being a medial muscular sphincter or diaphragm that divides the adenodactyl into a broad ental region and a narrower ectal region. The ectal part is the most glandular and here there is a broad zone of glandular tissue, whose structure is obscured by the copious secretions, interpolated between the lumen epithelium and the musculature. The total impression is that of a diverticulum of the atrium that has become heavily muscularized and glandularized (fig. 1B). This is especially clear in a not fully mature specimen of $P . d$. musculosa in which the musculature of the diverticulum is not so pronounced (fig. 1C), and also in $P$. occulta from Virginia (Kenk, 1969: fig. 12). Kenk has acknowledged in his description of this latter species that its adenodactyl differs in some details from that of the European species of the genus.

The function of these organs is unknown, but structurally and positionally the adenodactyls of Planaria torva and $P$. dactyligera are dissimilar. We do not regard them as homologous, as having a common origin. The specialized atrial diverticulum of $P$. dactyligera is comparable to the hollow glandular organs of some Dugesiidae and Dendrocoelidae (Weiss, 1910; Kenk, 1930). As Kenk rightly implies these are not adenodactyls and may well have been independently acquired by the different species and species groups. 

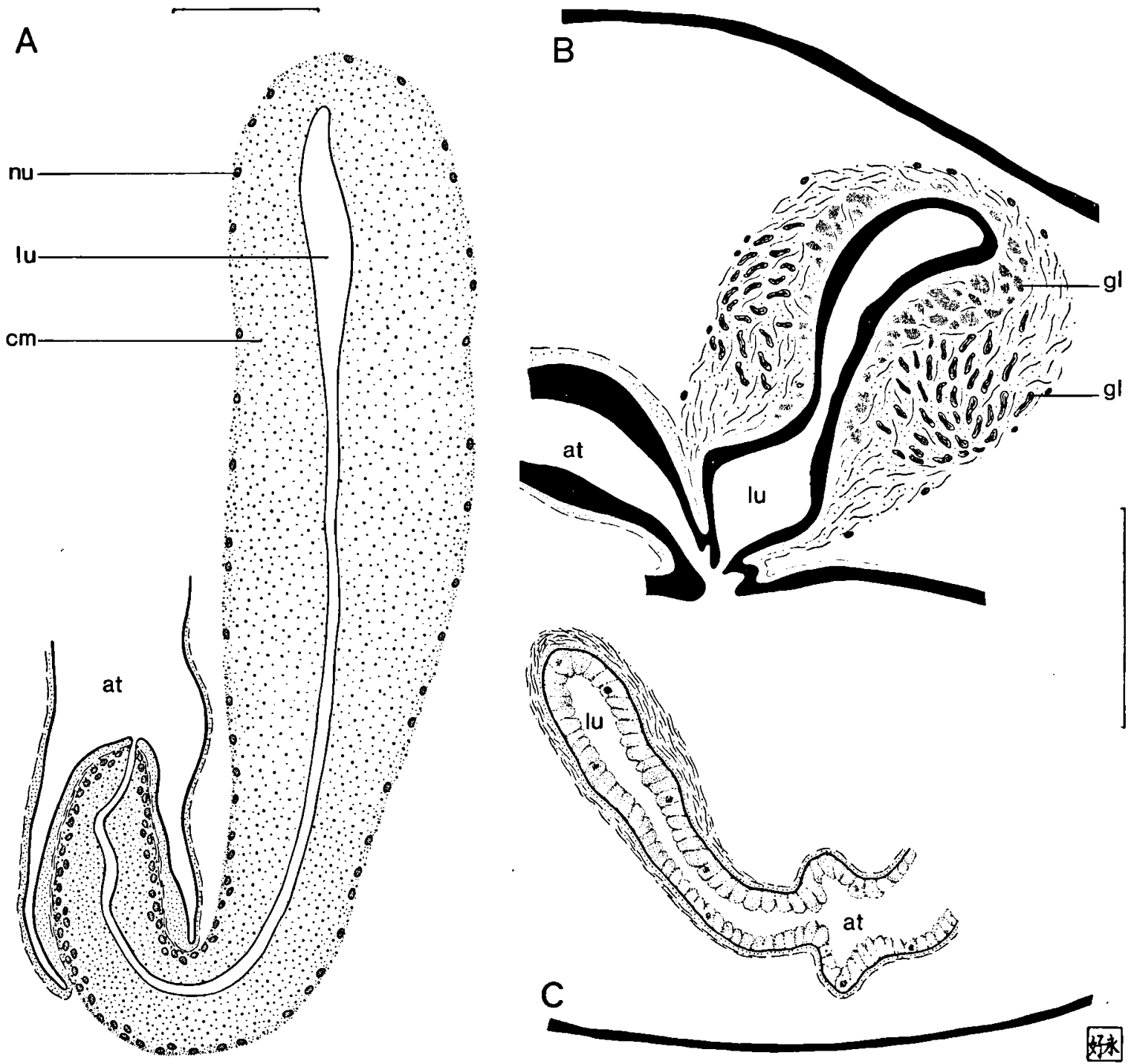

Fig. 1. Adenodactyls within the genus Planaria. A, frontal section through the adenodactyl of $P$. torva. B, sagittal section through the adenodactyl of $P$. dactyligera dactyligera. $C$, sagittal section through the adenodactyl of an immature $P$. dactyligera musculosa. All scale lines represent $100 \mu \mathrm{m}$. at $=$ atrium; $\mathrm{cm}=$ circular muscle; $\mathrm{gl}=$ glandular secretions; lu $=1 \mathrm{lumen}$ of adenodactyl; $\mathrm{nu}=$ nucleus. Drawings by Tran Thi Vinh Hao.

\section{KARYOLOGICAL CONSIDERATIONS}

The diploid complement of Planaria torva consists of 18 elements. The mean relative lengths and centromeric indices (c.i.) are given in table I; the karyotype is represented by the idiogram of fig. 2A. A conspicuous feature is the large size of chromosome 1 , which is a little over 1.3 times the size of the next element. Thereafter the elements decrease gradually in size. With respect to centromere position, five of the elements, including the largest and the three smallest pairs, are meta- centric (c.i. $>37$ ), three pairs are submetacentric $(37>$ c.i. $>25)$ and one pair, number 4 , is on the borderline between submeta- and subtelocentric.

These results are in agreement with the findings of Benazzi \& Puccinelli $(1961,1963)$ for Italian populations and with those of Melander (1963) for material from Sweden. Gametogenesis was not studied for the French populations, but Benazzi \& Puccinelli (1963) found meiosis to be normal in both the male and female lines, with 9 bivalents showing numerous chiasmata. 


\section{TABLE I}

Relative length and centromeric index of the 9 chromosome pairs of Planaria torva from France. Means and standard deviations from five mitotic metaphase plates.

\begin{tabular}{crrl}
$\begin{array}{c}\text { Chromo- } \\
\text { some }\end{array}$ & $\begin{array}{c}\text { Relative } \\
\text { length }\end{array}$ & $\begin{array}{c}\text { Centromeric } \\
\text { Index }\end{array}$ & Nomenclature \\
\hline 1 & $22.14 \pm 1.29$ & $46.37 \pm 2.73$ & metacentric \\
2 & $16.81 \pm 0.67$ & $25.62 \pm 2.15$ & submetacentric \\
3 & $14.53 \pm 0.35$ & $31.09 \pm 5.14$ & submetacentric \\
4 & $11.79 \pm 1.04$ & $25.77 \pm 0.74$ & submetacentric \\
5 & $9.74 \pm 0.71$ & $47.46 \pm 2.34$ & metacentric \\
6 & $8.04 \pm 0.44$ & $30.06 \pm 5.17$ & submetacentric \\
7 & $6.52 \pm 0.87$ & $43.94 \pm 5.35$ & metacentric \\
8 & $5.49 \pm 0.31$ & $39.58 \pm 1.96$ & metacentric \\
9 & $5.08 \pm 0.42$ & $40.13 \pm 2.04$ & metacentric \\
\hline
\end{tabular}
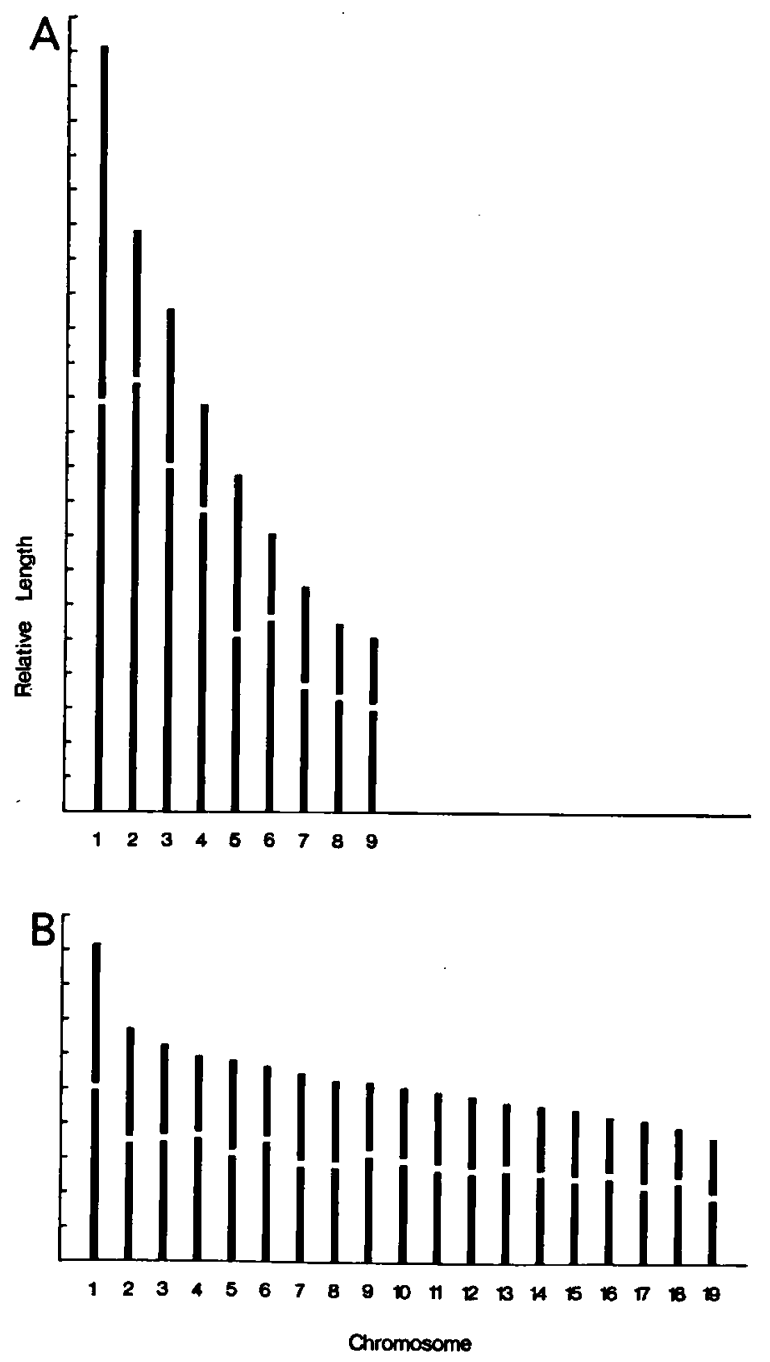

Fig. 2. Idiogram analyses of $\boldsymbol{A}$, Planaria torva, from the data in table I and B, Planaria dactyligera musculosa, from the data in table II. Diagrams by Tran Thi Vinh Hao.
The data for Planaria dactyligera are in sharp contrast to those just described for the European species. Both subspecies were identical karyologically (cf. figs. $3 \& 4$ ) and so data are given only for $P$. dactyligera musculosa which gave the most numerous, and clearest results. In this North American endemic the diploid complement comprises 38 elements. Mean relative lengths and centromeric indices for the 19 pairs are given in table II, and an idiogram is given in fig. 2B. Again the first pair of chromosomes is something over 1.3 times the length of the second pair, and the last 17 pairs decrease in length gradually, more so than in $P$. torva. With respect to centromere position most of the elements are metacentric. Chromosomes 6 and 16 are on the borderline of submetacentric and those numbered 4, 9, 13 and 18 approach this condition.

TABLE II

Relative length and centrometric index of the 19 chromosome pairs of Planaria dactyligera musculosa from North Carolina. Means and standard deviations from eight mitotic metaphase plates.

\begin{tabular}{cccl}
$\begin{array}{c}\text { Chromo- } \\
\text { some }\end{array}$ & $\begin{array}{c}\text { Relative } \\
\text { length }\end{array}$ & $\begin{array}{c}\text { Centromeric } \\
\text { Index }\end{array}$ & Nomenclature \\
\hline 1 & $9.15 \pm 0.44$ & $44.98 \pm 0.82$ & metacentric \\
2 & $6.72 \pm 0.16$ & $47.79 \pm 1.67$ & metacentric \\
3 & $6.28 \pm 0.21$ & $43.12 \pm 1.37$ & metacentric \\
4 & $5.96 \pm 0.23$ & $38.54 \pm 0.76$ & metacentric \\
5 & $5.81 \pm 0.21$ & $46.07 \pm 1.65$ & metacentric \\
6 & $5.66 \pm 0.21$ & $36.78 \pm 1.95$ & meta/sub- \\
& & & metacentric \\
7 & $5.45 \pm 0.10$ & $47.15 \pm 1.77$ & metacentric \\
8 & $5.23 \pm 0.17$ & $46.26 \pm 1.25$ & metacentric \\
9 & $5.21 \pm 0.14$ & $39.86 \pm 2.30$ & metacentric \\
10 & $5.04 \pm 0.15$ & $42.01 \pm 1.76$ & metacentric \\
11 & $4.96 \pm 0.07$ & $44.11 \pm 1.40$ & metacentric \\
12 & $4.81 \pm 0.07$ & $44.47 \pm 3.83$ & metacentric \\
13 & $4.64 \pm 0.15$ & $39.83 \pm 1.55$ & metacentric \\
14 & $4.55 \pm 0.07$ & $42.88 \pm 1.98$ & metacentric \\
15 & $4.44 \pm 0.13$ & $45.13 \pm 2.62$ & metacentric \\
16 & $4.25 \pm 0.17$ & $39.19 \pm 2.36$ & meta/sub- \\
& & & metacentric \\
17 & $4.12 \pm 0.16$ & $45.09 \pm 2.20$ & metacentric \\
18 & $3.92 \pm 0.29$ & $38.14 \pm 0.59$ & metacentric \\
19 & $3.62 \pm 0.29$ & $45.89 \pm 0.60$ & metacentric \\
\hline
\end{tabular}

Gametogenesis in both the male and female lines is normal. For spermatogenesis many figures of diakinesis were observed but sometimes they were difficult to analyse because of overlapping of the bivalents. However, in 10 spermatocytes $I$ an 


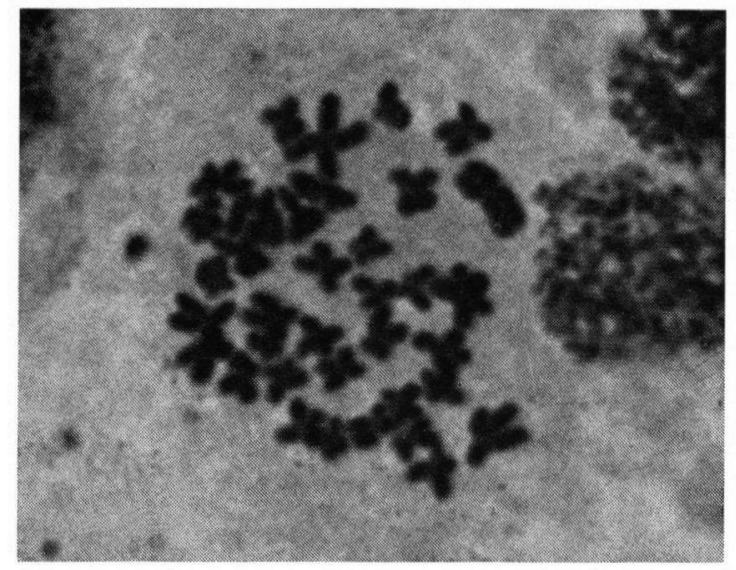

Fig. 3. Planaria dactyligera musculosa, chromosomes at mitotic metaphase.

undoubted number of 19 bivalents was observed, and most of them are ring-shaped because of the complete chiasma terminalization. In squashed ovaries we found oocytes in the pachytene stage. These also had 19 bivalents but no later stages were seen.

The karyotypes of Planaria torva and $P$. dactyligera musculosa obviously bear little resemblance to one another, neither in chromosome number and morphology, nor in the behaviour of the bivalents during spermatogenesis. In fact there is only one real similarity and that relates to the high relative length of the first pair of chromosomes, this being a feature even more pronounced in a large number of European and North American Planariidae (Benazzi \& Gourbault, 1974; Gourbault \& Ball, in preparation). In fact the karyotype of Planaria dactyligera is almost identical with that of Phagocata fawcetti from California (cf. fig. 2B with Ball \& Gourbault, 1975: fig. 3) and of a number of other Planariidae from eastern North America (Gourbault \& Ball, in preparation).

The karyological data are unequivocal. The karyotype of Planaria dactyligera is unlike that of $P$. torva, bears little resemblance to that of other European Planariidae, and is almost identical with that of several North American Planariidae. That these latter belong mostly to the genus Phagocata, an ill-def ined genus characterized only by primitive features (Ball \& Gourbault, 1975: 11-13; Ball, 1975: note 19) is not without interest. Karyologic-

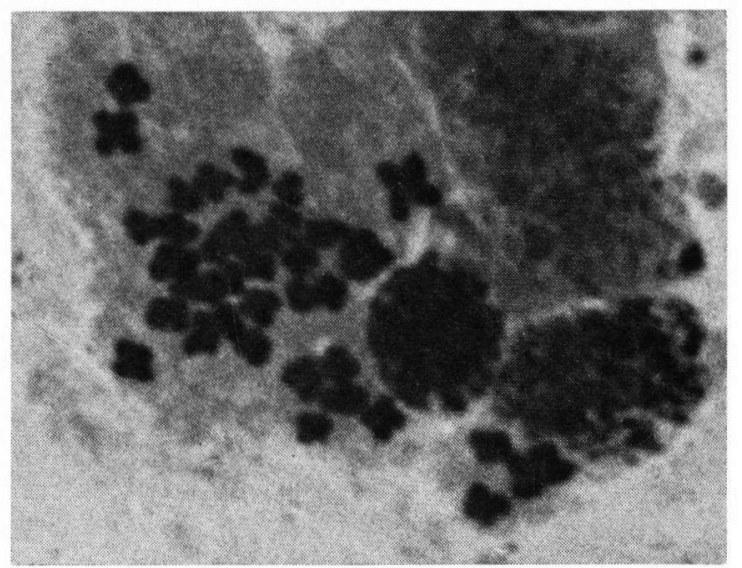

Fig. 4. Planaria dactyligera dactyligera, chromosomes at mitotic metaphase.

ally the affinities of $P$. dactyligera rest not with $P$. torva but with a group of North American planariids all of which, no doubt, have a common origin in, and are endemic to, North America. On present knowledge the karyotype of $P$. torva is unique and estimates of its derivation must await further studies of European forms.

\section{DISCUSSION AND CONCLUSIONS}

The monophyly of the genus Planaria as currently recognized rests solely on the presumed homologies between the adenodactyls of the three species (Kenk, 1969: 556). We have attempted to demonstrate on comparative anatomical grounds that this is not the case. Moreover, it is noteworthy that all the American species possess testes that extend only to the mouth region, a common feature in nearctic Phagocata species, whereas in $P$. torva they are throughout the body-length. Thus we assume that the American and European species have been derived independently from spatially and temporally segregated ancestors. The new karyological data are consistent with this viewpoint. The American species of Planaria are merely specialized species of Phagocata of the group characterized by a particular karyotype $(2 n=38)$ that is found neither in Planaria torva nor any other European freshwater planarian hitherto investigated karyologically (cf. Benazzi \& BenazziLentati, 1976).

In the light of these data we deny that Planaria is a monophyletic genus and that the amphiatlantic 
disjunction exhibited by the "genus" has any meaning in terms of the earlier biogeographical hypothesis (Ball, 1975). The retention of the genus in its present sense is misleading. The number of species involved is so small that the claim of convenience will not suffice for its justification, and it is less than convenient if it conveys erroneous biological information. So far as known there are no true amphiatlantic relationships exhibited by freshwater planarians.

It follows that the American species cannot be retained in the genus and our formal taxonomic proposals are as follows:

\section{Genus Planaria Müller, 1776.}

Type species: Fasciola torva Müller, 1774, designated Kenk, 1930.

Diagnosis: as given by Kenk, 1930: 293.

\section{Genus Paraplanaria gen. nov.}

Type species: Planaria dactyligera Kenk, 1935, here designated.

Diagnosis: Phagocata-like Planariidae with a musculo-glandular posterior diverticulum of the atrium.

Other species: Planaria occulta Kenk, 1969: 549.

The new name is intended to convey the concept of similarity, not relationship.

\section{ACKNOWLEDGEMENTS}

Liesbeth de Vries and Hilde Veenstra (Institute of Taxonomic Zoology, University of Amsterdam) collected our material from northern France and our fieldwork in North Carolina and Virginia was facilitated by Dr. Reinhardt Rieger (Chapel Hill, North Carolina). Further laboratory studies were carried out at the Department of Invertebrate Zoology, Royal Ontario Museum. Our work on the karyotaxonomy of North American planarians, of which this paper forms a small part, has been supported by the National Research Council of Canada through its cultural exchange programme and via operating grant A0016. For all this help we are grateful.

\section{REFERENCES}

BALI, I. R., 1975. Nature and formulation of biogeographical hypotheses. Syst. Zool., 24: 407-430.

- 1977. On the phylogenetic classification of aquatic planarians. In: T. G. Karling \& M. MeINANDER eds., The Alex Luther Centennial Symposium on Turbellaria. Acta zool. fenn., 154: 21-35.

Ball, I. R. \& N. Gourbault, 1975. The morphology, karyology, and taxonomy of a new freshwater planarian of the genus Phagocata from California (Platyhelminthes: Turbellaria). Life Sci. Contr., R. Ont. Mus., 105: 1-19.

Bali, I. R., T. B. ReYNoldson \& T. WARWICK, 1969. The taxonomy, habitat and distribution of the freshwater triclad Planaria torva (Platyhelminthes: Turbellaria) in Britain. J. Zool., Lond., 157: 99-123.

BenazzI, M. \& G. Benazzi-Lentati, 1976. Animal cytogenetics, 1. Platyhelminthes: 1-182 (Gebr. Borntraeger, Berlin/Stuttgart).

Benazzi, M. \& N. Gourbault, 1974. Etude caryologique de quelques populations hypogées de la planaire Phagocata (Fonticola) vitta (Dugès, 1830). Caryologia, 27: 467. 484.

Benazzi, M. \& I. Puccinelli, 1961. Il corredo cromosomico di Planaria torva (O. F. Müller). Atti Ass. Genet. ital., 7: 234-235.

\& - , 1963. Cariologia di Planaria torva (O. F. Müller). Caryologia, 16: 653-661.

Gourbault, N. \& I. R. Ball, in preparation. The comparative karyology of North American freshwater planarians.

KENK, R., 1930. Beiträge zum System der Probursalier (Tricladida paludicola). Zool. Anz., 59: 145-162; 259302.

_, 1935. Studies on Virginian triclads. J. Elisha Mitchell scient. Soc., 51: 79-133.

- 1969. Freshwater triclads (Turbellaria) of North America. I. The genus Planaria. Proc. biol. Soc. Wash., 82: $539-558$.

Melander, Y., 1963. Cytogenetic aspects of embryogenesis of Paludicola, Tricladida. Hereditas, 49: 119-166.

WeIss, A., 1910. Beiträge zur Kenntniss der australischen Turbellarien. I. Tricladen. Z. wiss. Zool., 94: 541-604.

Whitehouse, R. H., 1913. Zoological results of the Abor Expedition, 1911-12, xxii: Freshwater Planaria. Rec. Indian Mus., 8: 317-321. 